\title{
Performance Evaluation Of Organic Food Attributes To Increase Customer Satisfaction And Loyalty
}

\author{
Stevia Septiani ${ }^{1}$, Ujang Sumarwan ${ }^{2}$, Mukhamad Najib $^{3}$ \\ IPB University \\ \{steviaseptiani@apps.ipb.ac.id\}
}

\begin{abstract}
Organic food is one solution for global food sustainability in the future. Although its existence has a positive impact on farmers and consumers, the development of the domestic organic food market is still limited. This study aims to formulate a market development strategy for organic food products through evaluation of the marketing mix performance. Data were collected from 527 respondents in 5 big cities, namely Jakarta, Bandung, Semarang, Surabaya, and Bali. Data analysis methods used in this study include descriptive analysis, Importance Performance Analysis and Customer Satisfaction Index. In general, the profile of organic food consumers is dominated by women, the middle class who are well educated, and established age. The results showed that Price is an attribute of the marketing mix that is in the A quadrant which needs to be improved immediately. The majority of consumer's view that the quantity of organic food purchased is not in accordance with the value of the money they paid. In addition, the marketing mix such as product quality, price discounts, product availability, ease of access are very important attributes for consumers. In general, the Customer Satisfaction Index of organic food products is quite good $(71.28 \%)$.
\end{abstract}

Keywords: organic food; importance performance analysis; customer satisfaction index; market development; customer loyalty

\section{Introduction}

Food safety is one of the important issues in the world because it is related to the sustainability of the global food system in the future. One alternative in maintaining the balance of nature and sustainable food consumption is to use organic farming methods. The existence of organic agriculture in Indonesia has strategic benefits, because in addition to supporting food security, organic farming is also able to encourage local farmers to be more competitive. Central government support is shown through the "1000 organic village" program. Furthermore, AOI data shows that issues of food safety, health, environment, and taste are part of the reasons for consumers to choose healthy food (SPOI, 2019).

Globally, organic farming is gaining popularity, both from farmers and consumers. The agricultural area under organic cultivation has increased almost 5-fold in the last 20 years, from 15 million hectares in 2000, to about 71.5 million hectares in 2018 (FAO, 2020). Indonesia's prospects to become an organic food-producing country are very large. In the Asian region, Indonesia occupies the fourth position as the country with the largest organic farming area with a land area of 208042 ha and the number of producers as many as 17948 (FiBL \& IFOAM 2019). However, limited access and resources have made the productivity of organic agricultural 
land in Indonesia unable to meet the existing demand. According to data from the Indonesia Organic Alliance, in 2018 the domestic market demand for organic food experienced positive growth, particularly due to the development of online sales by several organic food distributors.

AOI's 2019 data provides an overview of the majority of organic consumers shopping through direct market channels, followed by online market access, supermarkets, and specialty stores. Interestingly, these organic consumers are also very strong with a community base, so that the community market is one of the alternatives for consumers to access organic products. Furthermore, the process of growing your own organic products is an alternative for the consumer market (SPOI, 2019). Sales growth of packaged organic food in Indonesia in 20172022 is predicted to reach $8.4 \%$ (globalorganictrade.com 2018).

Based on the findings, data on consumer access to organic products provides an overview of the increasing demand for organic food, motivating researchers to analyze the reasons behind consumer behavior (M. von Meyer-Höfer et al. 2015). Although there are many studies of consumer behavior modeling in organic markets, the debate about the determinants of organic food consumption provides conflicting evidence. Several studies have revealed that the majority of consumers have a positive attitude towards organic food, but the number of people who buy organic food regularly is still low (Pearson, Henryks, \& Jones, 2011).

Even in developed markets such as Germany, England, Denmark, the organic food market is dominated by occasional consumers who are not only motivated by altruistic aspects, but are more shaped by egoistic aspects such as greater perceived health, nutritional performance, and better taste of organic products. (Padilla-Bravo, Cordts, Schulze, \& Spiller, 2013; Meyer-Höfer et al. 2015). The organic food market in developing countries certainly has a different trend. Thus, research on organic food in emerging markets such as Indonesia is very important.

This study has two main objectives (1) identifying consumer characteristics and buying behavior of organic food (2) evaluating the performance of the organic food marketing mix and consumer satisfaction. This study aims to provide guidelines for farmers/producers, distributors, retailers, marketers, and policy makers to determine effective organic food marketing strategies in the Indonesian market.

\section{Literature Review}

\subsection{Marketing Mix of Organic Food in Indonesia}

Marketing mix is a fundamental point in the marketing system. According to Kotler and Keller (2016) marketing mix is a 4P mix, namely product (product), place (place), promotion (promotion) and price (price). In developing the organic product market, the organic product market development approach is in line with the opinion of Ottoman (2011). Ottoman (2011) in Bryl (2015) identifies the difference between the green marketing paradigm and conventional marketing using a marketing mix approach. The green marketing paradigm is building values, education building communities, and word-of-mouth marketing.

Meanwhile, conventional marketing includes benefits, sales, one-way communication, and paid advertising. The 2019 AOI provides an overview of the majority of organic consumers shopping through direct market channels, followed by online market access, supermarkets, and specialty stores. Interestingly, these organic consumers are also very strong with a community base, so that the community market is an alternative for consumers to access organic products. Furthermore, the process of growing your own organic products is an alternative for the consumer market (SPOI, 2019). 


\subsection{Consumer Satisfaction and Loyalty on Organic product}

Satisfaction is the result of customer evaluation of a product or service by comparing the suitability between expectations and actual performance. Based on the results of previous studies, the key factor in consumer buying behavior towards organic products is trust (Lee, JenFu, and Yen, 2019; Curvelo et al., 2019; Canova, 2020; Melovic, 2020).

Furthermore, Curvelo et al., (2019) and Canova (2020) argue that the value received by consumers has an effect on the intensity of purchasing organic products. In addition, the health benefits received, security, and product packing claims add reasons to the decision to purchase organic products (Hensen et al. 2002; Melovic, 2019). The consistent intensity of purchasing organic products has an effect on consumer satisfaction and loyalty of organic products and agricultural sustainability. organic.

\section{Research Methods}

Primary data were collected through in-depth interviews and self-administered on the period of May-September 2018. The research samples came from the islands of Java and Bali which included residents of the capital cities in each province, namely: Jakarta, Bandung, Semarang, Surabaya and Denpasar. The sampling technique used is non-robability sampling, especially convenience sampling approach. The collected questionnaires were then cleaned, incomplete questionnaires were removed, so that the total questionnaires that could be continued in data processing amounted to 527 questionnaires.

The primary data was processed by descriptive analysis techniques to see the frequency distribution on consumer characteristics and buying behavior. Meanwhile, to analyze the performance evaluation of the organic food marketing mix using the Importance Performance Analysis (IPA) approach. The level of consumer satisfaction of organic food is reflected in the value of the Customer Satisfaction Index (CSI).

\section{Result}

\subsection{Organic Foods Profiles in Indonesia}

From the 527 respondents, it is known that in general consumers who purchase organic food belong to the category of middle class customers (monthly income Rp. 3 million -5 million by $29 \%$ ). Organic food consumers mostly well educated (75\% bachelor degree) and wellestablished families with a middle age of 20-29 years by $42.5 \%$ (Najib et.al 2021). The majority who buy organic food are women (69.8\%), married (58.4\%) and have children under 18 years old in their household (59.8\%).

These results are in line with research conducted by Hughner et al (2007) that consumers of organic food are groups with good education, middle age, more women who have children. More details can be seen in the following image. 


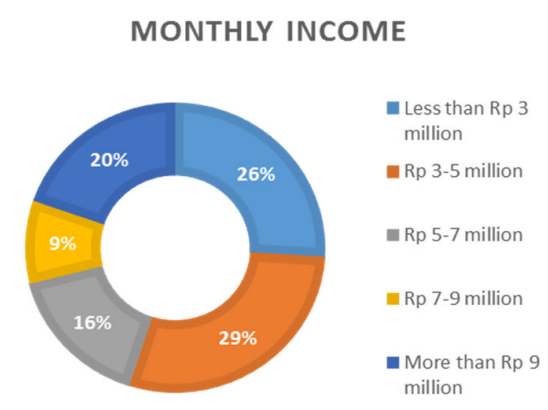

Fig 1. Demographic attributes of the respondents

The results on buying behavior of organic food show that consumers give a positive response to organic food. The organic food market in the future will experience growth. Although it is still included in the category of occasional customers where consumption of organic food has not become a daily routine, generally consumers buy organic food once a month $(35.3 \%)$. The types of organic food that are most often consumed sequentially are vegetables $(44.6 \%)$, rice $(22.8 \%)$ and fruit $(13.1 \%)$, with a monthly expenditure for organic food which is less than $\mathrm{Rp}$ 500000 by $54.3 \%$ (Najib et.al 2021). The premium price of organic food is still a barrier to consuming larger quantities. This result is in accordance with the research of Zander et al (2018) that price is one of the reasons for consumers not to buy organic food.

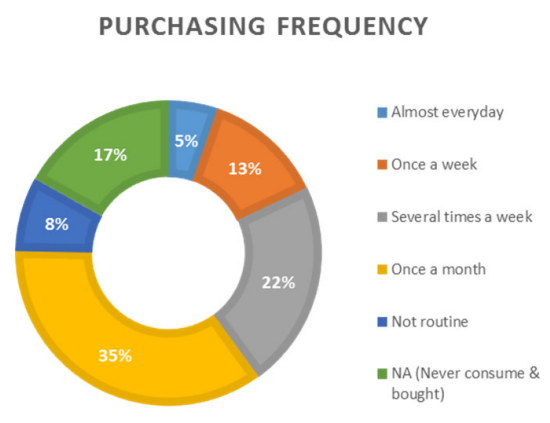

Fig 2. Purchasing behavior of the respondents

\subsection{Performance Evaluation of Organic Foods Marketing Mix in Indonesia}

The measurement of consumer satisfaction on the attributes of the organic food marketing mix is carried out using the Importance-Performance Analysis (IPA) and Customer Satisfaction Index (CSI) methods. The measurements are then represented in quadrants on the ImportancePerformance Matrix map. This mapping can show the attributes of the level of conformity between consumer expectations and the performance of the existing organic food marketing mix.

Based on the data obtained, from 527 respondents there are 89 respondents who have never consumed $\&$ have never bought, 6 respondents who have never consumed $\&$ have bought, 80 
respondents who have consumed \& have never bought, and 352 respondents who have consumed $\&$ have bought. Performance measurement and consumer satisfaction of organic food is focused on respondents with criteria that have ever consumed and/or bought. The ImportancePerformance Level diagram of the organic food marketing mix can be seen in the following.

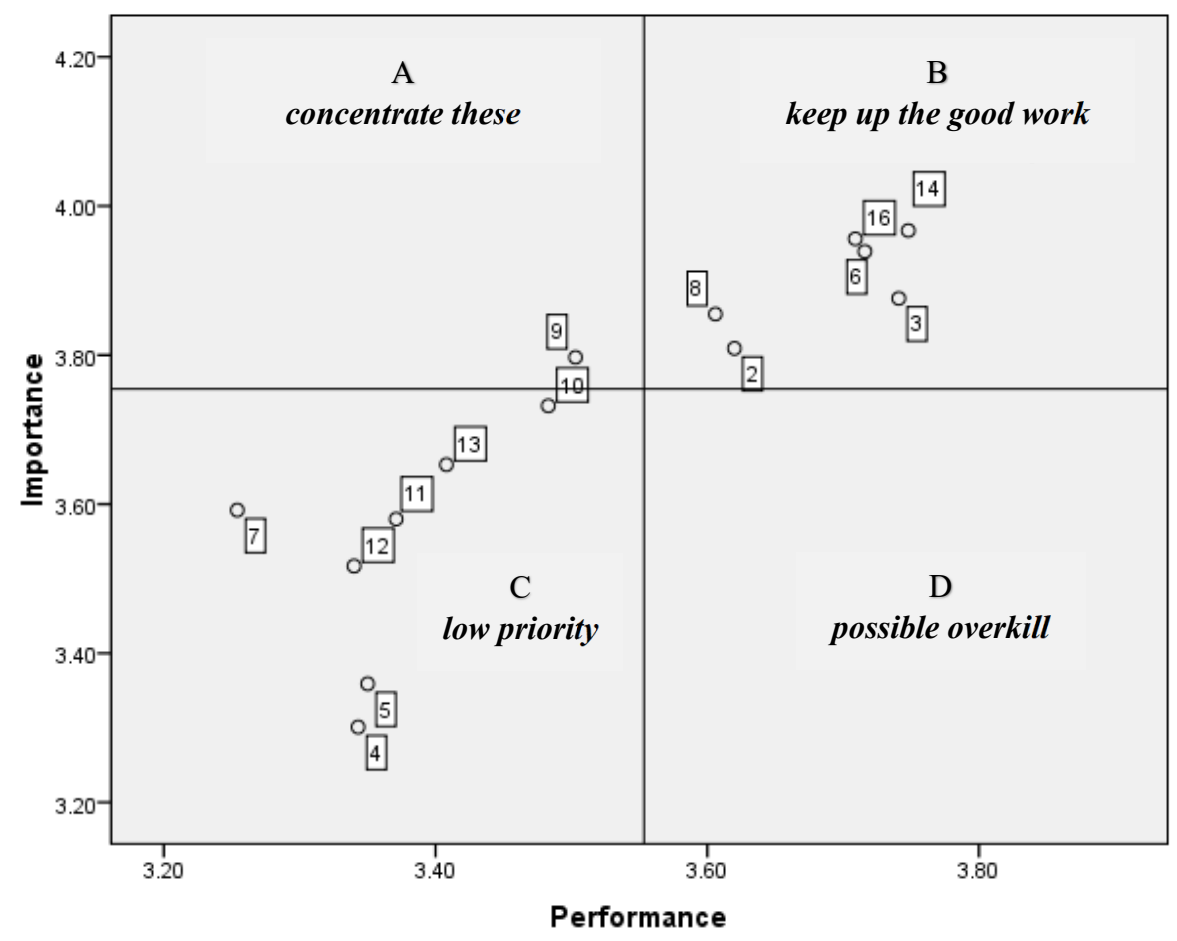

Fig 3. Purchasing behavior of the respondents

Quadrant A (concentrate these)

Quadrant A contains the attributes of the organic food marketing mix that have a high level of importance for consumers, but their performance is still not in line with consumer expectations. The attribute is attribute number 9 (PRICE4), which is the suitability of the quantity of organic food with the value of money paid. In this study, organic vegetables are the dominant type of organic food consumed by consumers. Generally, consumers feel that the price they pay for organic food products does not match the amount of product they get. Consumers want to get a quantity of products that are more than the value of the money they have spent to buy these organic food products.

\section{Quadrant B (keep up the good work)}

The attributes of the organic food marketing mix in quadrant B are considered important by consumers and their performance is as expected. The attributes into this quadrant must be maintained because all of these attributes are the benefits of the organic food marketing mix. The attributes are as follows: attribute number 1 (PRODUCT1) of better quality and guaranteed, attribute number 2 (PRODUCT2) of organic food products has a good reputation, attribute 
number 3 (PRODUCT3) is hygienic and good packaging of organic food, attribute number 6 (PRICE1) is discounted prices on organic food, attribute number 8 (PRICE3) is the suitability of the quality of organic food purchased with the value of the money, attribute number 14 (PLACE1) is a strategic place when buying organic food, attribute number 15 (PLACE2) ease of finding products, attribute number 16 (PLACE3) layout that makes it easy and comfortable when buying organic food.

\section{Quadrant C (low priority)}

Attributes in quadrant $\mathrm{C}$ are considered less important by consumers and have relatively low performance. The marketing mix of organic food which is in quadrant $\mathrm{C}$ is not a priority to be improved and needs more careful consideration if it is still implemented. This is because consumers have not felt the importance of the attributes that are in this quadrant. The attributes are as follows: attribute number 4 (PRODUCT4) of a well-known brand, attribute number 5 (PRODUCT5) of a long-standing brand reputation, attribute number 7 (PRICE2) inexpensive organic food prices, attribute number 10 (PRICE5) of products purchased according to the budget, attribute number 11 (PROMO1) an attractive advertisement about organic food, attribute number 12 (PROMO2) an attractive brochure/leaflet about organic food, attribute number 13 (PROMO3 ) an attractive sales promotion about organic food.

\section{Quadrant D (possible overkill)}

Quadrant D contains the attributes of the organic food marketing mix that are considered less important in its implementation, but consumers feel that the performance of these attributes is excessive. There are no attributes of the organic food marketing mix that fall into this quadrant.

Based on the Customer Satisfaction Index (CSI), the CSI value of the organic food marketing mix was $71.28 \%$. This indicates that consumers of organic food are satisfied with the marketing mix of organic food. When see in the CSI value criteria guidelines, this value is included in the "satisfactory" level. Various improvement strategies are needed to improve the performance of the organic food marketing mix so that the CSI value is at the maximum level.

Table 1. Guidelines for CSI score criteria

\begin{tabular}{|c|c|c|}
\hline No & Range & Description \\
\hline 1 & $25 \leq \mathrm{CSI}<43,75$ & Very unsatisfactory \\
\hline 2 & $43,75 \leq \mathrm{CSI}<62,5$ & Not satisfactory \\
\hline 3 & $62,5 \leq \mathrm{CSI}<81,25$ & Satisfactory \\
\hline 4 & $81,25 \leq \mathrm{CSI}<100$ & Very satisfactory \\
\hline
\end{tabular}

\section{Conclusion}

In general, the profile of organic food consumers is classified in the middle class segment, has a relatively high level of education, women are married and have children under the age of 18 years. The most popular type of organic food in Indonesia is the fresh product category, namely vegetables. The organic food market in Indonesia has the potential to continue to grow in the future. This can be seen from the purchasing patterns of consumers who have made organic food a product that is purchased every month. However, the frequency of consumption 
has not been regularly every day. The price factor is still an obstacle for most consumers in buying organic food. Based on the Importance-Performance map, the price attribute is the priority for improvement. The CSI value of organic food consumers is $71.28 \%$ which is at a satisfactory level.

Several strategic recommendations to develop the organic food market include organic food producers doing a slight price reduction by increasing the economy of scale through collaboration with organic farmer groups, more efficient distribution through placing organic products in the marketplace, maximize selling the product to the organic community, and sharpen the target market for consumers who already understand and love organic food.

\section{Acknowledgement}

This research was financially supported by research grant provided by the Ministry of Research, Technology and Higher Education of the Republic of Indonesia.

\section{References}

[1] Ajzen, I., 1991. The theory of planned behaviour. Organ. Behav. Hum. Decis. Process. 50, 179-211.

[2] Aertsens et.al (2009);

[3] Al-Swidi A, Muhammad Haroon Hafeez, Mohd Noor Mohd Shariff. (2013). The role of subjective norms in theory of planned behavior in the context of organic food consumption. British Food Journal. Vol. 116 Iss 10 pp. $1561-1580$.

[4] Annunziata, A., \& Vecchio, R., 2016. Organic farming and sustainability in food choices: an analysis of consumer preference in Southern Italy. Agriculture and Agricultural Science Procedia 8 (2016) $193-200$.

[5] Bryła P. 2015. The Development of Organic Food Market as An Element Of Sustainable Development Concept Implementation. Problemy Ekorozwoju - Problems Of Sustainable Development Vol. 10, No 1, 79-88.

[6] Byre M. Barbara. 2010. Sturctural Equation Modeling with AMOS Basic Concept, Application and Programming Second Edition. 2010 Taylor and Francis Group, LLC.

[7] Chen, M.-F. (2007). Consumer Attitudes and Purchase Intentions in Relation to Organic Foods in Taiwan: Moderating Effects of Food-Related Personality Traits. Food Quality and Preference, 10081021.

[8] Curvelo, I.C.G., Watanabe, E.A.d.M. and Alfinito, S. (2019), "Purchase intention of organic food under the influence of attributes, consumer trust and perceived value", Revista de Gestão, Vol. 26 No. 3, pp. 198-211. https://doi.org/10.1108/REGE-01-2018-0010

[9] FiBL \& IFOAM - Organics International. The World of Organic Agriculture Statistics \& Emerging Trends 2019.

[10] Hughner, R.S., McDonagh, P., Prothero, A., Shultz, C.J. and Stanton, J. (2007) Who are organic food consumers? A compilation and review of why people purchase organic food. Journal of Consumer Behaviour 6(5), 94-110.

[11] Ioannis Kareklas, Jeffrey R. Carlson \& Darrel D. Muehling. 2014. "I Eat Organic for My Benefit and Yours": Egoistic and Altruistic Considerations for Purchasing Organic Food and Their Implications for Advertising Strategists. Journal of Advertising, 43(1), 18-32.

[12] Lee TH, Chung-Jen Fu and Chen YY. 2020. Trust factors for organic foods: consumer buying behavior. British Food Journal, Vol. 122 No. 2, 2020. DOI 10.1108/BFJ-03-2019-0195

[13] Luigina Canova, ${ }^{*}$ Andrea Bobbio, and Anna Maria Manganelli. 2020. Buying Organic Food Products: The Role of Trust in the Theory of Planned Behavior. Front Psychol. 2020; 11: 575820. doi: $10.3389 /$ fpsyg.2020.575820 
[14] Marie von Meyer-Höfer, Evelyn Olea-Jaik, Carlos Antonio Padilla-Bravo \& Achim Spiller. Mature and Emerging Organic Markets: Modelling Consumer Attitude and Behaviour With Partial Least Square Approach. Journal of Food Products Marketing. 00:1-28, 2015.

[15] Melovic B, Cirovic D, Vulic BV, Dudic B, Gubiniova K. 2020. Attracting Green Consumers as a Basis for Creating Sustainable Marketing Strategy on the Organic Market-Relevance for Sustainable Agriculture Business Development. Foods. 9, 1552; doi:10.3390/foods9111552.

[16] Najib M, Sumarwan U, Septiani S, Waibel H, Suhartanto D \& Fahma F. (2021): Individual and SocioCultural Factors as Driving Forces of the Purchase Intention for Organic Food by Middle Class Consumers in Indonesia, Journal of International Food \& Agribusiness Marketing, DOI: $10.1080 / 08974438.2021 .1900015$

[17] Padilla-Bravo, C., Cordts, A., Schulze, B., \& Spiller, A. (2013). Assessing determinants of organic food consumption. Food Quality and Preference, 28, 60-70.

[18] Pearson, D., Henryks, J., \& Jones, H. (2011). Organic food: What we know (and do not know) about consumers. Renewable Agriculture and Food Systems, 26, 171-177.

[19] Schwartz, ShalomH. (1992), "Universals in the Content and Structure ofValues: Theoretical Advances and Empirical Tests in 20 Countries," in Advances in Experimental Social Psychology, vol. 25, Mark P. Zanna, ed., San Diego, CA: Academic Press, 1-65.

[20] Statistik Pertanian Organik Indonesia [SPOI]. 2019

[21] Tarkiainen, A., \& Sundqvist, S. (2005). Subjective Norms, Attitudes and Intention of Finnish Consumers in Buying Organic Food. British Food Journal , 808-822.

[22] Yeon Ho Shin \& Murat Hancer (2016) The role of attitude, subjectivenorm, perceived behavioral control, and moral norm in the intention to purchaselocal food products, Journal of Foodservice Business Research, 19:4, 338-351, DOI: 10.1080/15378020.2016.1181506

[23] Zander, Katrin., Schieenbecker, Rosa., and Hamm Ulrich. 2018. Consumer Behaviour in the Organic and Fair Trade Food Market in Europe. Fair Trade and Organic Agriculture: A Winning Combination? 51-60. CAB International. UK

[24] https://globalorganictrade.com/country/indonesia 